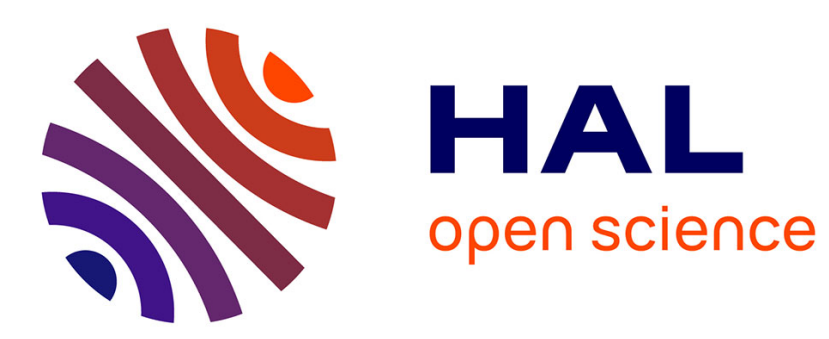

\title{
On Signalling and Screening in Markets with Asymmetric Information
}

Anastasios Dosis

\section{To cite this version:}

Anastasios Dosis. On Signalling and Screening in Markets with Asymmetric Information. 2016. hal01285190v2

\author{
HAL Id: hal-01285190 \\ https://essec.hal.science/hal-01285190v2 \\ Preprint submitted on 18 Mar 2016
}

HAL is a multi-disciplinary open access archive for the deposit and dissemination of scientific research documents, whether they are published or not. The documents may come from teaching and research institutions in France or abroad, or from public or private research centers.
L'archive ouverte pluridisciplinaire HAL, est destinée au dépôt et à la diffusion de documents scientifiques de niveau recherche, publiés ou non, émanant des établissements d'enseignement et de recherche français ou étrangers, des laboratoires publics ou privés. 


\title{
E \\ ESS EC \\ BUSINESS SCHOOL
}

\section{ON SIGNALLING AND SCREENING}

\author{
RESEARCH CENTER \\ ESSEC WORKING PAPER 1608
}

2016

Anastasios Dosis 


\title{
On Signalling and Screening in Markets with Asymmetric Information
}

\author{
Anastasios Dosis*
}

March 2, 2016

\begin{abstract}
The two games that are typically used to model markets with asymmetric information are the signalling game and the screening game. In the signalling game, an equilibrium may not be efficient because of the arbitrariness of off-the-equilibriumpath beliefs. In the screening game, a pure-strategy Nash equilibrium may fail to exist because of "cream-skimming" deviations. Perhaps surprisingly, I show how equilibrium generically exists and is efficient in a game that combines signalling and screening. The signalling part assures the existence of equilibrium, whereas the screening part prevents non-efficient allocations from being supported as equilibrium allocations.
\end{abstract}

KEYWORDS: Signalling, screening, asymmetric information, information economics, existence, efficiency

JEL CLASSIFICATION: D82, D86

\section{INTRODUCTION}

- Motivation. Almost every modern microeconomics textbook features a full chapter on information economics. Within this chapter, one finds two distinctive games used to describe markets with asymmetric information. First, in the signalling game, introduced by Spence (1973) and further extended by Maskin and Tirole (1992), an informed party proposes a menu of contracts to an uninformed party who accepts or rejects. Second, in the screening game, originally introduced by Rothschild and Stiglitz (1976), at

*Department of Economics - ESSEC Business School and THEMA, 3 Av. Bernard Hirsch, B.P. - 50105, Cergy, 95021, France, Email: dosis@essec.com. This paper was a chapter of my PhD thesis. I would like to thank Gorkem Celik, Patricia Charlety, John Geanakoplos, Kobi Glazer, Peter Hammond, Ilan Kremer, JeanPhilippe Lefort, Nicola Pavanini, Motty Perry, Herakles Polemarchakis, Phil Reny, David Ronayne, Paolo Siconolfi, Guillaume Sublet and Radu Vrancenau as well as participants at the Annual General Equilibrium conference at the Cowles Foundation, Yale 2013, the Symposium for Advances in Economic Theory (SAET), Paris 2013, the Annual Conference of European Public Choice Society (EPCS), Zurich 2013, and seminar attendees at the Max Plank Institute, Bonn 2013. All errors are my own. 
least two symmetric, uninformed parties compete in menus of contracts to attract an informed party. Notably, the equilibrium sets of these two games vary drastically. In the signalling game, a generic indeterminacy of inefficient equilibria can be sustained because of the arbitrariness of off-the-equilibrium-path beliefs. In the screening game, a pure-strategy equilibrium may fail to exist because the uninformed parties may have "cream-skimming" profitable deviations. A natural question arises: What happens in a game combining both signalling and screening? Perhaps surprisingly, I show that an equilibrium generically exists and is efficient in such a game.

To demonstrate this result, I employ a stylised competitive insurance market. In this market, there is a consumer who can suffer a costly accident and seek insurance. Two symmetric firms provide insurance. The two possible types of consumers are high-risk and low-risk consumers. The high-risk type is more prone to suffering the accident than the low-risk type is. An insurance contract specifies a premium and an indemnity in case the accident occurs. In the first part of the paper, I contrast the sets of equilibria of the signalling game vis-à-vis the screening game. In the signalling game, the consumer proposes a menu of contracts to both companies. If at least one company accepts the proposal, the consumer selects a contract from at most one of the companies that accepted. If both companies reject, then the consumer remains uninsured. In the screening game, the two companies simultaneously and independently compete in menus of contracts. The consumer then selects a contract from at most one company. The least-costly separating allocation is defined as the allocation that maximises the payoff of both consumer types within the set of incentive-compatible allocations that are individually rational for each company type by type. As shown by Maskin and Tirole (1992), every incentive-compatible allocation that yields positive profits (relative to the prior beliefs) and weakly dominates the least-costly separating allocation can be supported as a perfect Bayesian equilibrium in the signalling game. By contrast, as shown by Mas-Colell, Whinston, and Green (1995) and Jehle and Reny (2011), a pure-strategy Nash equilibrium in the screening game exists and is unique in terms of payoffs if and only if the least-costly separating allocation is efficient. Therefore, the two games agree in their market outcome predictions if and only if the least-costly separating allocation is efficient.

I then analyse a simple combination of the two games, which I call the signallingscreening game. Similar to the signalling game, in the first stage, the consumer proposes a menu of contracts. In the second stage, each company accepts or rejects. If both companies reject, the game ends. If at least one company accepts, the game moves to the third stage. Similar to the screening game, in the third stage, each company that accepted can propose a menu of contracts to the consumer. In the fourth stage, the consumer selects at most one company and a contract from those he proposed in the first stage or from those that this company proposed in the third stage. The result may be striking. If the least-costly separating allocation is efficient, then the equilibrium set of the signallingscreening game is payoff-equivalent to both the signalling and screening games. If the least-costly separating allocation is not efficient, then an allocation is an equilibrium allocation if and only if it is efficient and weakly dominates the least-costly separating allocation.

For an intuitive explanation of this result, note that the first two stages of the game are the signalling stages. As in the signalling game, with his offer, every type of consumer 
can guarantee that his payoff does not fall below the least-costly separating allocation. The third stage is the screening stage. This stage is indispensable to avoid the inefficiency result of the signalling game. Suppose that the consumer has made a "non-efficient" offer in the first stage and is unable to deviate, as in the signalling game, because both companies would infer that the deviation comes from a high-risk consumer and would therefore reject any dominating offer. The addition of the third stage of the game solves this problem. In particular, I show that even if the consumer is unable to deviate, one of the companies always has an incentive to do so. Therefore, a necessary condition for an equilibrium allocation is that it must be efficient. A natural question then arises: Why does a company not deviate from an efficient menu of contracts, as in the screening game? The fourth stage of the game prevents this from happening. In particular, note that in the signalling-screening game, the consumer has the right to either select one of the menus proposed by one of the companies or his own menu by any company that accepted his offer. This very fact creates barriers to "cream-skimming" profitable deviations. Indeed, one can construct a sequentially rational strategy for the consumer such that both types propose an efficient allocation in the first stage and both types select a contract with the company that offers a "cream-skimming" menu of contracts in the third stage. Recall that no type is worse off compared with his offer to contract with any company because, by definition, he has access to this offer in the last stage of the game. This suffices to render any deviation on the company side unprofitable.

Related Literature. Since the seminal contribution of Spence (1973), a vast body of literature on signalling games has emerged. Overall, signalling games have been highly successful in explaining a variety of observed phenomena, such as corporate financial structure (Myers and Majluf 1984), limit pricing (Milgrom and Roberts 1982), advertising (Milgrom and Roberts 1986), etc., which conventional economic theory has struggled to explain. The indeterminacy of equilibria inevitably led researchers to search for appropriate refinements that restrict off-the-equilibrium-path beliefs; such works include Banks and Sobel (1987) and Cho and Kreps (1987). One of the various applications of signalling games (and the closest to this paper) is in the theory of contracts. As previously mentioned, Maskin and Tirole (1992) examine a signalling game in which the informed party is the principal who makes a take-it-or-leave-it offer of a mechanism to an uniformed party. I extensively analyse the equilibria of this signalling game in the simplest possible model and compare these to the signalling-screening game.

Following the contribution of Rothschild and Stiglitz (1976), screening games have been used in modelling competition in markets with adverse selection. The striking result of the non-existence of equilibrium established by Rothschild and Stiglitz (1976) inevitably attracted considerable attention and motivated researchers to search for alternative (weaker) definitions of equilibrium. The most well-known definitions are from Wilson (1977) and Riley (1979). Applications of screening games are found in the analysis of insurance, credit and labour markets, in which uninformed companies attempt to "screen" informed consumers through menus of contracts; examples of such works include Miyazaki (1977), Spence (1978), and Bester (1985). Recently, researchers have shown a renewed interest in analysing games in which the set of equilibrium allocations includes only efficient allocations. Such works include Asheim and Nilssen (1996), Di- 
asakos and Koufopoulos (2011), Mimra and Wambach (2011), Netzer and Scheuer (2014), Picard (2014) and Dosis (2016a). In particular, in Dosis (2016a), I take a mechanism design approach, and I construct a decentralised mechanism in which an equilibrium always exists and is efficient. The mechanism takes the following form: all companies in the market simultaneously and independently offer two menus of contracts. I call one of these menus the "private menu" and the other the "public menu". The distinctive characteristic of the mechanism is that the union of all public menus must be offered by all active companies. The private menu concerns only the company that offers it. In Dosis (2016a), I show that the set of equilibrium allocations includes the entire set of constrained Pareto-efficient allocations. By contrast, in this paper, I characterise the equilibrium set of a game that combines signalling and screening. The set of equilibrium allocations of the signallingscreening game differs from that in Dosis (2016a) because the payoff of no type can fall below the least-costly separating allocation. To the best of my knowledge, this is the first paper that combines signalling and screening.

The remainder of the paper is organised as follows: In Section 2, I describe the stylised insurance market. In Section 3, I describe the signalling and screening games and their sets of equilibria. In Section 4, I introduce the signalling-screening game, and I analyse its set of equilibria. In Section 5, I provide a brief conclusion. In Appendix A, I show how the results are generalised in environments with more than two types.

\section{THE MODEL}

- The Insurance Market. Consider a single consumer and two insurance companies. The consumer can be one of two possible types, $i=H, L$. Both companies believe that the probability of the consumer being of type $i$ is $\lambda_{i}$. Each type $i$ starts with wealth $W$ and can suffer damage equal to $d$ with probability $\theta_{i}$, where $\theta_{H}>\theta_{L}$. A contract specifies a premium $p$ and a benefit (indemnity) $b$. A contract is denoted as $c=(p, b) \in \mathbb{R}_{+}^{2}$. The expected utility of type $i$ from contract $c$ is $U_{i}(c)=\left(1-\theta_{i}\right) u(W-p)+\theta_{i} u(W-d-p+b)$, where $u^{\prime}>0$ and $u^{\prime \prime}<0$. The expected profit of the company that provides contract $c$ is equal to $\pi_{i}(c)=p-\theta_{i} b^{1}$

Allocations. An allocation is a pair of contracts indexed by the set of types, i.e., $\left(c_{H}, c_{L}\right) \in \mathbb{R}_{+}^{4}$. In the language of mechanism design, an allocation is simply a direct revelation mechanism. An allocation $\left(c_{H}, c_{L}\right)$ is incentive compatible if and only if $U_{H}\left(c_{H}\right) \geq$ $U_{H}\left(c_{L}\right)$ and $U_{L}\left(c_{L}\right) \geq U_{L}\left(c_{H}\right)$. One of the benchmark incentive-compatible allocations is known as the least-costly separating allocation.

Definition 2.1. The least-costly separating allocation is denoted as $\left(\hat{c}_{H}, \hat{c}_{L}\right)$ and satisfies the following conditions: $\hat{b}_{H}=d, \hat{p}_{H}=\theta_{H} d$, and $U_{L}\left(\hat{c}_{L}\right)=U_{L}\left(\hat{c}_{H}\right), \pi_{L}\left(\hat{c}_{L}\right)=0$.

The least-costly separating allocation is depicted in Figure 1. The horizontal axis represents the benefit, and the vertical axis represents the premium. The two straight lines are the zero profit lines, one for each type, and the curves are the indifference curves of the two types.

\footnotetext{
${ }^{1}$ In Appendix A, I generalise the results to environment with more than two types.
} 


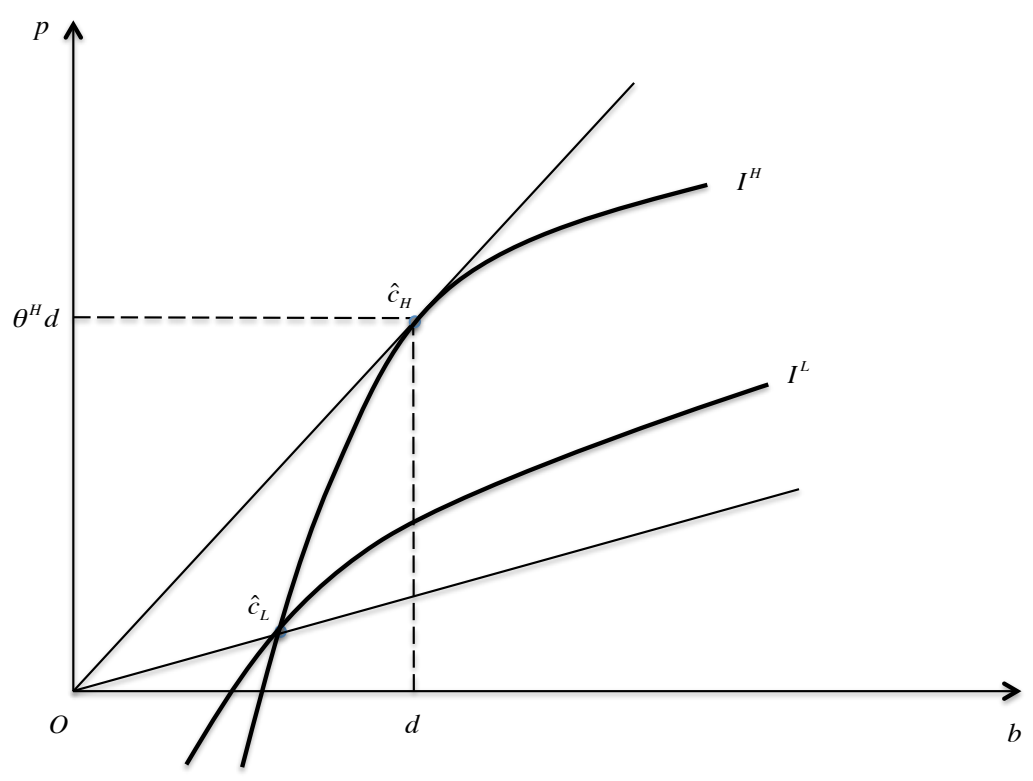

Figure 1: The least-costly separating allocation

I now define efficient allocations.

Definition 2.2. An allocation $\left(c_{H}, c_{L}\right)$ is efficient if and only if (i) $U_{H}\left(c_{H}\right) \geq U_{H}\left(c_{L}\right)$ and $U_{L}\left(c_{L}\right) \geq U_{L}\left(c_{H}\right)$, (ii) $\sum_{i=H, L} \lambda_{i} \pi_{i}\left(c_{i}\right) \geq 0$, and (iii) there exists no allocation $\left(\tilde{c}_{H}, \tilde{c}_{L}\right)$ that satisfies (i) and (ii) and, moreover, $U_{i}\left(\tilde{c}_{i}\right) \geq U_{i}\left(c_{i}\right)$ for every $i$ with a strict inequality for at least one $i$.

Note that efficiency is defined with respect to the consumer's payoff. In other words, I concentrate on the subset of Pareto-efficient allocations that maximise the payoff of the consumer, i.e., a weighted average of the utilities of the two types, subject to the incentive compatibility constraint and the individual rationality constraint of a representative company relative to the prior beliefs. Given the stated assumptions, one can prove the following result:

Lemma 2.3. If $\left(c_{H}, c_{L}\right)$ is an efficient allocation, then $\sum_{i=H, L} \lambda_{i} \pi_{i}\left(c_{i}\right)=0$.

Proof. Consider an incentive-compatible allocation $\left(c_{H}, c_{L}\right)$ such that $\sum_{i=H, L} \lambda_{i} \pi_{i}\left(c_{i}\right)>$ 0 . Take allocation $\left(\tilde{c}_{H}, \tilde{c}_{L}\right)$, where $u\left(W-\tilde{p}_{i}\right)=q u\left(W-p_{i}\right)+(1-q) u\left(W-\theta_{L} d\right)$ and $u\left(W-d-\tilde{p}_{i}+\tilde{b}_{i}\right)=q u\left(W-d-p_{i}+b_{i}\right)+(1-q) u\left(W-\theta_{L} d\right)$. Clearly, $U_{i}\left(\tilde{c}_{i}\right)>U_{i}\left(c_{i}\right)$ for every $i=H, L$ and $0<q<1$. Because $u^{\prime \prime}<0, W-\tilde{p}_{i}<q\left(W-p_{i}\right)+(1-q)\left(W-\theta_{L} d\right)$, or

$$
\tilde{p}_{i}>q p_{i}-(1-q) \theta_{L} d
$$

Similarly,

$$
\tilde{p}_{i}-\tilde{b}_{i}>q\left(p_{i}-b_{i}\right)-(1-q)\left(\theta_{L} d\right)
$$

Multiplying (1i) by $1-\theta_{i}$ and (2i) by $\theta_{i}$ and summing, one obtains

$$
\tilde{p}_{i}-\theta_{i} \tilde{b}_{i}>q\left(p_{i}-\theta_{i} b_{i}\right)-(1-q) \theta_{L} d
$$


which can be rewritten as

$$
\pi_{i}\left(\tilde{c}_{i}\right)>q \pi_{i}\left(c_{i}\right)-(1-q) \theta_{L} d
$$

Multiplying (4i) by $\lambda_{i}$ and summing over $i=H, L$, one obtains

$$
\sum_{i} \lambda_{i} \pi_{i}\left(\tilde{c}_{i}\right)>q \sum_{i} \lambda_{i} \pi_{i}\left(c_{i}\right)-(1-q) \theta_{L} d
$$

which, for a sufficiently small $q$, is strictly higher than zero. Hence, $\left(c_{H}, c_{L}\right)$ cannot be efficient.

An equilibrium allocation is an allocation that results in the equilibrium outcome of a game between the consumer and the companies when all players use their equilibrium strategies.

\section{SigNALLING VS. SCREENING}

The first benchmark model related to this paper is a variant of the signalling model introduced by Maskin and Tirole (1992). Maskin and Tirole (1992) study an extensive form game with three stages. I henceforth refer to this game as the signalling game. In the first stage, the consumer proposes a pair of contracts. In the second stage, each company accepts or rejects the proposal. If both companies reject, the game ends. If at least one company accepts, the game moves to the third stage. In the third stage, the consumer selects a company and a contract from those he offered in Stage 1. ${ }^{2}$ Maskin and Tirole (1992) prove that an allocation $\left(c_{H}, c_{L}\right)$ is an equilibrium allocation in the signalling game if and only if it satisfies the following conditions:

$$
\begin{array}{cl}
\left(I C_{H, L}\right) & U_{H}\left(c_{H}\right) \geq U_{H}\left(c_{L}\right) \\
\left(I C_{L, H}\right) & U_{L}\left(c_{L}\right) \geq U_{L}\left(c_{H}\right) \\
\left(L C S_{i}\right) & U_{i}\left(c_{i}\right) \geq U_{i}\left(\hat{c}_{i}\right) \forall i \\
(P P) & \sum_{i=H, L} \lambda_{i} \pi_{i}\left(c_{i}\right) \geq 0
\end{array}
$$

The formal proof can be found in Maskin and Tirole (1992). The intuition behind this characterisation of equilibrium is the following. $\left(I C_{H, L}\right),\left(I C_{L, H}\right)$ and $(P P)$ in the "only if" part is rather straightforward. An equilibrium allocation must be incentive compatible and individually rational for the companies. For $\left(L C S_{H}\right)$ and $\left(L C S_{L}\right)$, consider any of the types, and assume that his equilibrium payoff is strictly lower than that provided by the least-costly separating contract. Suppose that in the first stage, the consumer proposes a strictly incentive-compatible menu of contracts that is arbitrarily close to the least-costly separating menu of contracts. Maskin and Tirole (1992) show that such

\footnotetext{
${ }^{2}$ The main difference between the signalling game explained in textbooks and the game examined here is the opportunity given to the consumer to propose a pair of contracts rather than a single contract. This difference notwithstanding, the game is a standard signalling game.
} 
a menu exists given the underlying assumptions. Then, at least one company should accept the proposal because, regardless of her belief, this menu makes strictly positive profits that contradict the definition of equilibrium. ${ }^{3}$ Because this applies to every contract arbitrarily close to the least-costly separating menu of contracts, the lower bound in the equilibrium payoff of every type is the payoff from the least-costly separating contract. Now, suppose that in the first stage, both types propose a menu of contracts satisfying $\left(I C_{H, L}\right),\left(I C_{L, H}\right),\left(L C S_{H}\right),\left(L C S_{L}\right)$ and $(P P)$. Such a menu is depicted in Figure 2. ${ }^{4}$ One company accepts, and in the third stage, both types select contract $\bar{c}$. The question is whether, for all other possible menus of contracts that are strictly preferred by at least one type, some beliefs exist such that both companies reject the proposal. Maskin and Tirole (1992) show that such beliefs exist. ${ }^{5}$

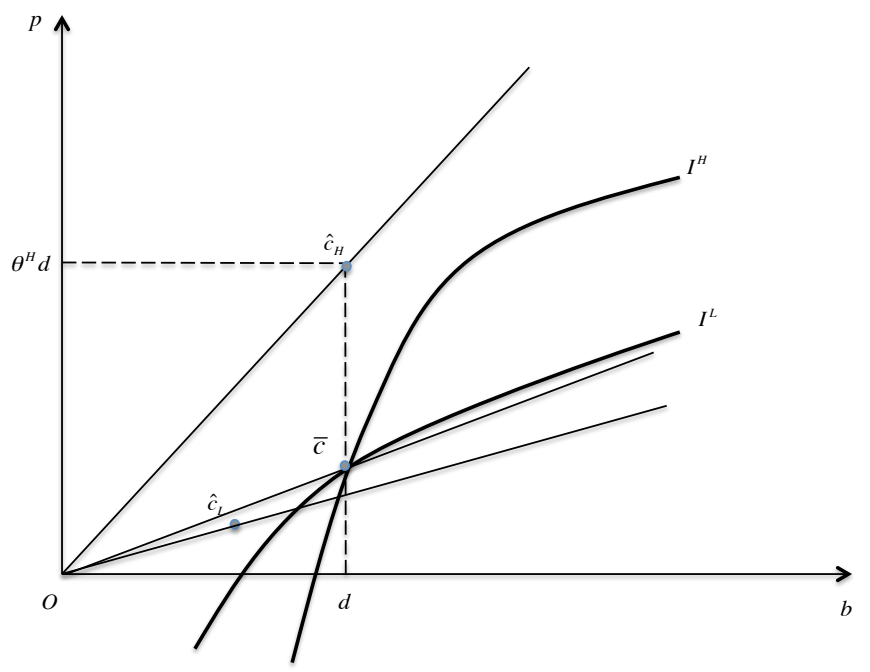

Figure 2: $(\bar{c}, \bar{c})$ is an equilibrium menu of contracts in the signalling game.

Proposition 1 has two fundamental implications. First, the equilibrium of the signalling game is unique if and only if the least-costly separating allocation is efficient. Second, if the least-costly separating allocation is not efficient, then the set of equilibrium allocations includes allocations that are not efficient. This result is a consequence of the arbitrariness of off-the-equilibrium-path beliefs and is common in games that include some information transmission.

The second benchmark model is that examined by Rothschild and Stiglitz (1976).

\footnotetext{
${ }^{3}$ This relies on the fact that the menu of contracts proposed by the consumer is strictly incentive compatible. Therefore, revealing his true type is a strictly dominant strategy in the third stage for the consumer.

${ }^{4}$ The menu of contracts depicted in Figure (2) corresponds to the only "pooling" menu of contracts that is efficient. For more details, see Crocker and Snow (1985).

${ }^{5}$ Note that in Figure 2, for every incentive-compatible menu of contracts that dominates the least-costly separating menu of contracts, one of the two contracts is not individually rational for the company. The offthe-equilibrium-path beliefs can then be determined as follows. For every menu of contracts that provides a higher payoff for at least one of the types than menu $(\bar{c}, \bar{c})$, both companies believe that the consumer is of type $L$ with certainty. Based on these beliefs, both companies should reject the proposal of the consumer if he makes an offer that provides a payoff higher than menu $(\bar{c}, \bar{c})$ to at least one type. Based on these strategies, no type has an incentive to deviate unilaterally.
} 
Here, I present a variant of this model as it was presented in textbooks such as MasColell, Whinston, and Green (1995) and Jehle and Reny (2011). ${ }^{6}$ These authors consider the following game, which I will henceforth call the screening game. There are two stages. In the first stage, each company simultaneously and independently offers a menu of contracts. In the second stage, the consumer selects a contract from at most one company. Rothschild and Stiglitz (1976) show that if the least-costly separating allocation is efficient, then it is the unique equilibrium allocation in the screening game. If the least-costly separating allocation is not efficient, then an equilibrium in pure strategies does not exist in the screening game.

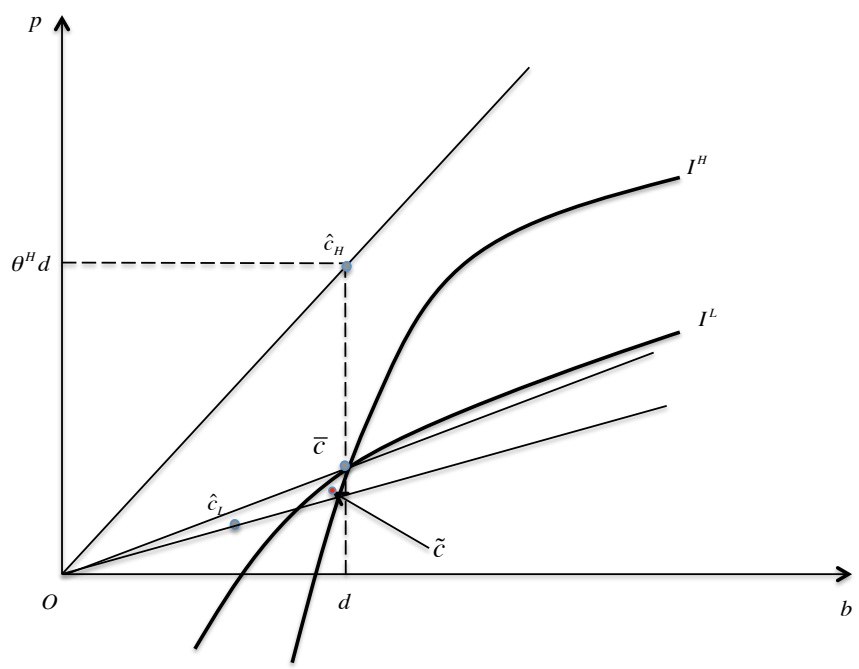

Figure 3: $(\bar{c}, \bar{c})$ is not an equilibrium in the screening game because $(\tilde{c}, \tilde{c})$ constitutes a "cream-skimming" deviation. If Company A offers menu of contracts $(\bar{c}, \bar{c})$, then Company $\mathrm{B}$, by offering menu $(\tilde{c}, \tilde{c})$, attracts only the low-risk type and makes strictly positive profits.

Therefore, the set of pure-strategy equilibria is a singleton (in terms of payoffs) when the least-costly separating menu of contracts is efficient, but it is the empty set when the least-costly separating menu of contracts is not efficient. For formal proofs, one can refer to Mas-Colell, Whinston, and Green (1995), Jehle and Reny (2011), or Dosis (2016b). The intuition behind the result is the following. First, one can show that a menu of contracts is an equilibrium menu of contracts only if it is efficient. This is the "Bertrand-type" feature of the game. Indeed, for any non-efficient menu of contracts, there exists another menu that results in higher profits if introduced by the same company. Second, when the least-costly separating allocation is efficient, an equilibrium can be constructed in which both companies offer this menu of contracts and no company can unilaterally deviate profitably. When the least-costly separating allocation is not efficient, efficiency entails cross-subsidisation. In other words, one type necessarily subsidises the other type, as depicted in Figure (2). One can then show that there exists no equilibrium in which the

\footnotetext{
${ }^{6}$ This approach was chosen because the models examined by Mas-Colell, Whinston, and Green (1995) and Jehle and Reny (2011) have more "modern" game-theoretic flavour and allow companies to offer menus of contracts. See also Dosis (2016b) for the generalisation of their results.
} 
contract for at least one type makes strictly positive profits. For every such menu, a profitable deviation exists, as depicted in Figure (3). A contradiction arises with the first point, and hence, an equilibrium in pure strategies does not exist.

\section{The SignalLing-Screening GAME}

- The Signalling-Screening Game. Now, let us consider a model that combines both games. As such, consider the following four-stage game, which I call the signallingscreening game. In the first stage, the consumer proposes a menu of contracts $\left(c_{1}, c_{2}\right)$. In the second stage, each company accepts or rejects. If both companies reject, then the game ends. If at least one company accepts, the game moves to the third stage. In the third stage, each company that accepted can propose a new menu of contracts. In the fourth stage, the consumer selects one company and chooses either one of the contracts he proposed in the first stage or a contract proposed by the company.

A strategy for the consumer specifies a menu of contracts for every possible type in the first stage of the game and a choice of a contract for every possible history of play in the fourth stage. A strategy for a company specifies a decision to accept or reject for every possible history of play in the second stage and a choice of a menu of contracts for every possible history in the third stage. A belief system specifies a probability distribution over the two types for every possible history of play (i.e., for every menu of contracts in the first stage).

I consider only the pure-strategy perfect Bayesian equilibria of this game. A perfect Bayesian equilibrium is a set of strategies (one for each player) and a belief system such that (i) the strategy of each player is sequentially rational given the beliefs and (ii) the beliefs are determined Bayes' rule given the players' equilibrium strategies.

A perhaps striking result is obtained:

Proposition 4.1. An allocation $\left(c_{H}, c_{L}\right)$ is an equilibrium allocation if and only if (i) it is efficient and (ii) $U_{i}\left(c_{i}\right) \geq U_{i}\left(\hat{c}_{i}\right)$ for every $i$.

The idea of the proof can be readily summarised as follows. First, consider the "only if" part. Note that the proof that $u_{i}\left(c_{i}\right) \geq u_{i}\left(\hat{c}_{i}\right)$ for every $i$ is identical to Maskin and Tirole (1992) and, hence, is omitted for obvious reasons. The following lemma facilitates the proof.

Lemma 4.2. In every pure-strategy equilibrium, both types offer the same menu of contracts.

PROOF: Suppose that there exists a pure-strategy equilibrium in which the two types propose a different menu of contracts. It is straightforward to observe that in any purestrategy equilibrium with full separation, the maximum payoff for the high-risk type is $U_{H}\left(\hat{c}_{H}\right)$. In a different occasion, after the proposal of the high-risk type, both companies would reject. Then, suppose that in equilibrium, after his proposal, the low-risk type contracts with Company A. Because Company B can always make an offer in the third stage of the game, competition will eliminate any positive profits. Therefore, the only viable equilibrium contract for the low-risk type is $\left(\theta_{L} d, \theta_{L} d\right)$ (i.e., the contract that the low-risk type would receive if the types were observable). This, however, contradicts the condition of no unilateral deviation of the equilibrium because in such a case, the high-risk 
type would have an incentive to deviate and pretend to be a low-risk type. Q.E.D.

Then, assume that there exists an equilibrium allocation $\left(c_{H}, c_{L}\right)$ that is not efficient. Thus, because of Lemma (2.3), there exists an allocation $\left(\bar{c}_{H}, \bar{c}_{L}\right)$ such that $U_{i}\left(\bar{c}_{i}\right)>U_{i}\left(c_{i}\right)$ for every $i$ and $\sum_{i} \lambda_{i} \pi_{i}\left(\bar{c}_{i}\right)>0$. I showed in Lemma (4.2) that in every pure-strategy equilibrium, both types offer the same menu of contracts. Two cases are possible: either $\pi_{i}\left(c_{i}\right)=0$ for every $i$, or $\pi_{j}\left(c_{j}\right)<0$ for some $j$. In the first case, in equilibrium, the two types might contract with a different company. In the second case, in equilibrium, both types necessarily contract with the same company. Otherwise the company that contracts with the high-risk type makes losses. In both cases, one of the companies (or both) clearly has a profitable unilateral deviation. In particular, by offering the pair of contracts $\left(\bar{c}_{H}, \bar{c}_{L}\right)$, the company attracts both types and makes strictly positive profits. This contradicts the condition of no unilateral deviation in the definition of equilibrium, and hence, $\left(c_{H}, c_{L}\right)$ cannot be an equilibrium allocation.

For the "if" part, consider the following strategies: both types offer the pair of contracts $\left(\bar{c}_{H}, \bar{c}_{L}\right)$ (i.e., an efficient allocation satisfying $U_{i}\left(\bar{c}_{i}\right) \geq U_{i}\left(\hat{c}_{i}\right)$ for every $i$ ), and both types contract with Company A if both companies offer $\left(\bar{c}_{H}, \bar{c}_{L}\right)$. If some company unilaterally offers a different pair of contracts $\left(\tilde{c}_{H}, \tilde{c}_{L}\right)$, then both types contract with this company. Each company accepts and offers $\left(\bar{c}_{H}, \bar{c}_{L}\right)$ if the offer of the consumer is $\left(\bar{c}_{H}, \bar{c}_{L}\right)$. Each company rejects if the offer of the consumer $\left(\tilde{c}_{1}, \tilde{c}_{2}\right) \neq\left(\bar{c}_{H}, \bar{c}_{L}\right)$ is such that

$$
\max _{c \in\left\{\tilde{c}_{1}, \tilde{c}_{2}\right\}} U_{H}(c)>U_{H}\left(\hat{c}_{H}\right)
$$

If both types offer $\left(\bar{c}_{H}, \bar{c}_{L}\right)$, then the posterior beliefs remain equal to the prior beliefs. For every other offer, the posterior beliefs are updated to $(1,0)$, i.e. both companies believe with certainty that the high-risk type is deviating. ${ }^{7}$ One can easily confirm that the strategies described above constitute equilibrium strategies. Based on the beliefs held by the two companies, no player has an incentive to deviate unilaterally.

Remarks. The following point is critical for the existence of equilibrium and thus deserves further discussion: in the signalling-screening game, the consumer has the right to select either one of the menus proposed by one of the companies or his menu by any company that accepted his offer. An initial question that arises involves how the equilibrium set varies when the companies can fully disregard the offer of the consumer and merely offer their own menus of contracts. In such a case, one can easily show that the equilibrium set of the game becomes payoff equivalent to that of the screening game. However, the stage in which the consumer makes an offer then becomes questionable. In particular, why is the consumer allowed to offer something that he can never select? For a signalling-screening game to make sense, it must allow the informed party to have access to all possible offers.

A related question is whether this choice can somehow become endogenous. To that extent, I emphasise that a payoff-equivalent game is one in which the consumer selects

\footnotetext{
${ }^{7}$ Recall that the same characterisation of beliefs was given in the characterisation of the equilibrium set by Maskin and Tirole (1992).
} 
a menu of contracts in the first stage of the game and whether he commits to this menu. Commitment means that any company that accepts his offer must allow the consumer to select a contract from the menu he offered in the first stage even if this company makes another offer in the third stage. In this game, one can show that if the least-costly separating menu of contracts is efficient, then commitment plays no particular role. Nonetheless, if the least-costly separating menu of contracts is not efficient, then in equilibrium, the consumer offers an efficient menu of contracts and commits to this menu. In this case, no company has a unilaterally profitable deviation.

Finally, one can consider the addition of the screening part after the signalling part as a "refinement" of the equilibrium set of the signalling game. ${ }^{8}$ In particular, note that the signalling game admits a large number of equilibria. One can argue that most of them are implausible because they are supported by "unreasonable" off-the-equilibrium-path beliefs. Equilibria exist that are strictly dominated for both types. As we observed, the addition of the screening game eliminates all these equilibria and thus "refines" the set of equilibrium allocations of the signalling game.

\section{CONCLUSION}

In this paper, I revisited the two common games used to model markets with asymmetric information: the signalling game and the screening game. I compared the set of equilibrium allocations of these two games and I highlighted the differences. Then, I examined a game that combines signalling and screening. I showed that in such a game, the set of pure-strategy equilibrium allocations is not empty, in contrast to that in the pure screening game, and every equilibrium allocation is efficient, in contrast to that in the signalling game.

\section{REFERENCES}

Asheim, Geir B., and Tore Nilssen, "Non-Discriminating Renegotiation in a Competitive Insurance Market," European Economic Review, 40 (1996), 1717-1736.

Banks, Jeffrey S., and Joel Sobel, "Equilibrium Selection in Signaling Games," Econometrica, 55 (1987), 647-661.

Bester, Helmut, "Screening vs. Rationing in Credit Markets with Imperfect Information," American Economic Review, 75 (1985), 850-855.

Cho, In-Koo, and David M. Kreps, "Signaling Games and Stable Equilibria," The Quarterly Journal of Economics, 102 (1987), 179-221.

Crocker, Keith J., and Arthur Snow, "The Efficiency of Competitive Equilibria in Insurance Markets with Asymmetric Information," Journal of Public Economics, 26 (1985), 207-219.

Diasakos, Theodoros, and Kostas Koufopoulos, "Efficient Nash Equilibrium under Adverse Selection," Working Paper, 2011, available at: http://papers.ssrn.com/sol3/ Papers.cfm?abstract_id=1944825.

\footnotetext{
${ }^{8}$ I would like to thank Jean-Philippe Lefort for suggesting this interpretation.
} 
Dosis, Anastasios, "An Efficient Mechanism for Competitive Markets with Adverse Selection," Working Paper, 2016a, available at: http://ssrn . com/abstract=2666964.

- "Bertrand Competition and the Existence of Pure Strategy Nash Equilibrium in Markets with Adverse Selection," Working Paper, 2016b, available at: http://papers . ssrn.com/sol3/papers.cfm?abstract_id=2666967.

Jehle, Geoffrey Alexander, and Philip J. Reny, Advanced Microeconomic Theory, 3rd ed. (Pearson Education, 2011).

Mas-Colell, Andreu, Michael Dennis Whinston, and Jerry R. Green, Microeconomic Theory, vol. 1 (New York: Oxford University Press, 1995).

Maskin, Eric, and Jean Tirole, "The Principal-Agent Relationship with an Informed Principal, II: Common Values," Econometrica, 60 (1992), 1-42.

Milgrom, Paul, and John Roberts, "Limit Pricing and Entry under Incomplete Information: An Equilibrium Analysis," Econometrica, 50 (1982), 443-459.

_ , "Price and Advertising Signals of Product Quality," Journal of Political Economy, 94 (1986), 796-821.

Mimra, Wanda, and Achim Wambach, "A Game-Theoretic Foundation for the Wilson Equilibrium in Competitive Insurance Markets with Adverse Selection," CESifo Working Paper Series No. 3412, 2011, available at: http://papers.ssrn.com/sol3/papers . cfm?abstract_id $=1808672$.

Miyazaki, Hajime, "The Rat Race and Internal Labor Markets," The Bell Journal of Economics, 8 (1977), 394-418.

Myers, Stewart C., and Nicholas S. Majluf, "Corporate Financing and Investment Decisions When Firms Have Information That Investors Do Not Have," Journal of Financial Economics, 13 (1984), 187-221.

Netzer, Nick, and Florian Scheuer, "A Game Theoretic Foundation of Competitive Equilibria with Adverse Selection," International Economic Review, 55 (2014), 399-422.

Picard, Pierre, "Participating Insurance Contracts and the Rothschild-Stiglitz Equilibrium Puzzle," The Geneva Risk and Insurance Review, 39 (2014), 153-175.

Riley, John G., "Informational Equilibrium,” Econometrica, 47 (1979), 331-359.

Rothschild, Michael, and Joseph Stiglitz, "Equilibrium in Competitive Insurance Markets: An Essay on the Economics of Imperfect Information," The Quarterly Journal of Economics, 90 (1976), 629-649.

Spence, Michael, "Job Market Signaling," The Quarterly Journal of Economics, 87 (1973), 355-374. 
—, "Product Differentiation and Performance in Insurance Markets," Journal of Public Economics, 10 (1978), 427-447.

Wilson, Charles, "A Model of Insurance Markets with Incomplete Information," Journal of Economic Theory, 16 (1977), 167-207.

\section{Appendix A: Generalisation of the Results to More than Two Types}

One assumption that might appear worrisome is the restriction to only two types. Assuming only two types simplifies the exposition and facilitates diagrammatic analysis. Here, I show that none of the results rely on this assumption. To do so, first I introduce some new notation. Let $I=\{1, \ldots, n\}$ be the set of possible types, with a representative element $i$, and $\theta_{i}$ the probability that type $i$ suffers the accident. Let us assume that $\theta_{i}<\theta_{i+1}$ for every $i=1, \ldots, n-1$. To keep the notation as close as possible to the main part of the paper, let $\lambda_{i}^{0}$ denote the prior probability that the type is $i$, with $\sum_{i} \lambda_{i}^{0}=1$. Similarly, the posterior probability, i.e. the probability in the beginning of the second stage, is denoted as $\lambda_{i}^{1}$. Following the notation in the main part of the paper, a contract is denoted as $c=(p, b) \in \mathbb{R}_{+}^{2}$. The expected utility of type $i$ from contract $c$ is $U_{i}(c)=\left(1-\theta_{i}\right) u(W-p)+\theta_{i} u(W-d-p+b)$, where $u^{\prime}>0$ and $u^{\prime \prime}<0$. The expected profit of the company that provides contract $c$ is equal to $\pi_{i}(c)=p-\theta_{i} b$.

To prove the "only if" part of Proposition (4.1), let $\left(I_{a}\right)_{a=1}^{A}$ be a partition of the type space, i.e. $I_{1} \cup I_{2} \cup \ldots \cup I_{A}=I$, where $I_{a}, I_{a^{\prime}}$ are mutually exclusive for every $a, a^{\prime}$. Assume that all types in $I_{a}$ propose the same menu of contracts $\left(c^{i}\right)_{i \in I_{a}}$. The posterior beliefs are derived by Bayes rule:

$$
\lambda_{i}^{1}=\frac{\lambda_{i}^{0}}{\sum_{i \in I_{a}} \lambda_{i}^{0}}
$$

Assume that $\left(c^{i}\right)_{i \in I_{a}}$ is not efficient relative to beliefs $\left(\lambda_{i}^{i}\right)_{i \in I_{a}}$. By a straightforward extension of Lemma (2.3), one can show that there exists $\left(\bar{c}^{i}\right)_{i \in I_{a}}$ such that $U_{i}\left(\bar{c}_{i}\right)>U_{i}\left(c_{i}\right)$ for every $i \in I_{a}$ and $\sum_{i \in I_{a}} \lambda_{i}^{1} \pi_{i}\left(\bar{c}_{i}\right)>0$. More specifically, one can easily show that if $\sum_{i \in I_{a}} \lambda_{i}^{1} \pi_{i}\left(c_{i}\right)>0$, then for every $\varepsilon>0$ (small enough), $\sum_{i \in I_{a}} \lambda_{i}^{1} \pi_{i}\left(\bar{c}_{i}\right)>\sum_{i \in I_{a}} \lambda_{i}^{1} \pi_{i}\left(c_{i}\right)-\varepsilon$. As in the proof of Proposition (4.1), two cases are possible: either $\pi_{i}\left(c_{i}\right)=0$ for every $i \in I_{a}$, or $\sum_{i \in I_{a}} \lambda_{i}^{1} \pi_{i}\left(c_{i}\right)>0$. In the first case, both companies make zero profits. In the second case, one can easily see that there is at least one company, say Company A, that makes profits strictly less than $\sum_{i \in I_{a}} \lambda_{i}^{1} \pi_{i}\left(c_{i}\right)$. It is evident that in both cases, Company A has a unilateral profitable deviation. By introducing $\left(\bar{c}^{i}\right)_{i \in I_{a}}$, it can attract all types in $I_{a}$ and make profits strictly higher than the one it makes in $\left(c^{i}\right)_{i \in I_{a}}$. Therefore, $\left(c^{i}\right)_{i \in I_{a}}$ cannot be an equilibrium allocation.

Consider now partition $\left(I_{a}\right)_{a=1}^{A}$ and the allocation $\left(c_{i}\right)_{i \in I}=\left\{c_{i} \in\left(c_{j}\right)_{j \in I_{a}}: a=1, \ldots, A\right\}$. Assume that $\left(c_{i}\right)_{i \in I_{a}}$ is efficient for every $a$ relative to the posterior beliefs derived from Bayes rule, but $\left(c_{i}\right)_{i \in I}$ is not efficient relative to the prior beliefs. The profit of $\left(c_{i}\right)_{i \in I}$ is $\sum_{i \in I} \lambda_{i}^{0} \pi_{i}\left(c_{i}\right) \geq 0$ because of Bayes rule. From Definition (2.2), there exists $\left(\bar{c}_{i}\right)_{i \in I}$ such that $U_{i}\left(\bar{c}_{i}\right)>U_{i}\left(c_{i}\right)$ for every $i \in I$ and $\sum_{i \in I} \lambda_{i}^{0} \pi_{i}\left(\bar{c}_{i}\right)>0$. Moreover, there exists $a$ such 
that $\sum_{i \in I_{a}} \lambda_{i}^{0} \pi_{i}\left(\bar{c}_{i}\right)>0$. Dividing both sides of the latter inequality by $\sum_{i \in I_{a}} \lambda_{i}^{0}$, it becomes $\sum_{i \in I} \lambda_{i}^{1} \pi_{i}\left(\bar{c}_{i}\right)>0$, which contradicts Definition (2.2). Therefore, every equilibrium allocation is efficient relative to the prior beliefs.

The proof of the "if" part of Proposition (4.1) is a straightforward extension of that with two types and therefore is omitted. 


\section{PARIS}

ESSEC Business School

3, avenue Bernard-Hirsch

CS 50105 Cergy

95021 Cergy-Pontoise Cedex

France

Tél. + $33(0) 134433000$

www.essec.fr
ESSEC Executive Education

CNIT BP 230

92053 Paris-La Défense

France

Tél. + $33(0) 146924900$

www.executive-education.essec.fr
ESSEC Asia Pacific

2 One-North Gateway

Singapore 138502

Tél. +65 68849780

www.essec.edu/asia

\section{SINGAPOUR}

Contact :

Centre de Recherche

+33 (0)134433091

research.center@essec.fr

ISSN 1291-9616 